\title{
CRACK INFLUENCE ON A PIPE WITH DOUBLE SLOPE UNDER INTERNAL PRESSURE: NUMERICAL SIMULATION WITH XFEM
}

\author{
SAlMi Houda ${ }^{1 *}$, HACHIM ABdelilah ${ }^{1,2}$, EL Bhilat HanaN ${ }^{1}$ \\ AND EL HAD KHALID ${ }^{1,2}$ \\ ${ }^{1}$ Hassan II University of Casablanca, National Higher School of Mechanics (ENSEM), \\ Laboratory of Control and Mechanical Characterization of Materials and Structures, \\ Casablanca, Morocco \\ ${ }^{2}$ Institute of Maritime Studies, Laboratory of Materials and Structures \\ Casablanca, Morocco \\ *Corresponding author: houda.salmi111@gmail.com
}

(Received: 14 $4^{\text {th }}$ April 2020; Accepted: $9^{\text {th }}$ May 2020; Published on-line: $4^{\text {th }}$ July 2020)

\begin{abstract}
This work analyses the effect of elliptical cracks on a pipe with double slope thickness transition, using the extended finite element method (XFEM), level sets were defined to describe the three-dimensional (3D) cracks. The Computation of the stress intensity factors (SIFs) of cracks is performed. The values of SIFs are compared between straight pipes and pipes with a double (single) slope thickness transition. The results show that the XFEM is an effective tool for modelling cracks in pipes. A pressurized pipe with double slope thickness transition is more sensitive to the defect in comparison with another type of pipe. Parameters of the transition zone have an effect on stress intensity factors, precisely, the parameters of the first thickness transition are more influential on the gravity of the defect compared to the second thickness transition.
\end{abstract}

ABSTRAK: Kajian ini menganalisa kesan retakan elips pada paip dengan peralihan ketebalan cerun berganda, menggunakan kaedah elemen terhingga dipanjangkan (XFEM), set tahap ditentukan bagi menentukan keretakan tiga dimensi (3D). Pengiraan faktor intensiti tekanan (SIF) retakan dilakukan. Nilai SIF dibandingkan antara paip lurus dan paip peralihan ketebalan cerun berganda (tunggal). Hasil kajian menunjukkan bahawa XFEM adalah alat yang berkesan bagi memodel keretakan paip. Paip bertekanan mengikut peralihan ketebalan cerun berganda, lebih sensitif terhadap kecacatan berbanding paip lain. Parameter zon peralihan mempunyai pengaruh terhadap faktor intensiti tegangan, tepatnya, parameter peralihan ketebalan pertama lebih mempengaruhi pada graviti kecacatan berbanding dengan peralihan ketebalan kedua.

KEYWORDS: extended finite element method (XFEM); pipe with double slope thickness transition; stress intensity factors (SIFs); three-dimensional cracks

\section{INTRODUCTION}

Presently, pressure equipment is used in various applications, such as energy production and chemical industry [1-4]. In the field of pressure equipment, cylindrical or spherical structures are often found, those shells can be affected by axi-symmetric or semielliptical internal or external cracks, it is then very important to evaluate the influence of these cracks on pressure equipment [5]. 
The French Alternative Energies and Atomic Energy Commission (CEA) [6] developed the finite element software (Castem) for structural and fluid mechanics [7]. CEA [6-8] used the finite element method (FEM) to investigate straight pipes with circumferential cracks. The field of pressure equipment also deals with the thickness of transition pipes, these pipes are classified into two types: transitions with a single slope and transitions with a double slope $[3,4]$. Those structures correspond to a connection between two cylinders of the same internal radius but with different thicknesses, those structures are subjected to circumferential cracks at the base of the thickness transition, those defects are modelled as cracks located in a pipe of uniform thickness $t[1,3,4]$.

Using FEM, Rahman et al. [1] evaluated the effect of the thickness transition zone on the crack opening displacement (COD), [1] showed that the thickness transition produces a dissymmetric distribution of the COD on the crack lips. Hariri $[3,4]$ used 3D finite element method (FEM) to study transition with a single slope containing elliptical crack subjected to tensile stress and bending moment, the result showed that for elastic plastic material, the thickness transition zone is the weakest position of the whole pipe.

The traditional finite element calculations have a cumbersome cost in the modelling of a crack. The accuracy of the results in the FEM depends on the mesh refinement, but a fine mesh implies a large number of nodes, so it requires a long calculation time [8]. Hence, XFEM is introduced to facilitate the solving of crack problems in complex geometries. In this work, the XFEM is used to analyse in 3D the external circumferential elliptical cracks in the thickness transition zone. In this method, the standard finite element approximation is locally enriched to discontinuities modelling $[9,10]$. For stationary cracks, the XFEM gives an accurate result, thanks to enrichment functions even with coarse meshes near the crack tip [9]. The XFEM was initiated by Belytschko and Black [11]. Stolarska et al. [12] coupled between the level set method (LSM) and XFEM to investigate the problem of cracks.

In the field of pressurized equipment, [13] used the XFEM to study the fracture behaviour of pipes under internal detonation loads. Sharma [14] performed a numerical investigation with XFEM to evaluate the stress intensity factor of a semi-elliptical crack in a pipe band.

Using the XFEM to investigate the effect of the crack on a thickness transition with two slopes besides evaluating the influence of transition zone on SIF were however not treated in [3], also, taking account of internal pressure was required to complete the work in [3]. The purpose of this work is the application of XFEM to evaluate the effect of a 3D external circumferential crack in thickness transition with a double slope in a pipe and investigate the effect of the parameters of the transition zone on SIF.

\section{XFEM METHODOLOGY}

\subsection{XFEM Formulation}

Using enrichment functions, the displacement approximation $U$ is given by Eq. (1) [9]:

$U(x)=\sum_{i \in N} N_{i}(x) u_{i}+\sum_{i \in N_{\alpha}} N_{i}(x)\left(H(x)-H\left(x_{i}\right)\right) a_{i}+\sum_{i \in N_{f}}\left[N_{i}(x)\left(\sum_{\alpha=1}^{4}\left(\beta_{\alpha}(x)-\beta_{\alpha}\left(x_{i}\right)\right) b_{i}^{\alpha}\right)\right]$

where $N_{i}$ is the standard finite element (FE) function of node $i . u_{i}$ is an unknown of the standard FE part at a node $i$. $N$ is a set of all nodes in the domain. $N_{d} \subset N$ is a nodal subset of the enrichment Heaviside function $\mathrm{H}(\mathrm{x})$. 


$$
H(x)=\left\{\begin{aligned}
1 & \text { if } \varphi(x)>0 \\
-1 & \text { otherwise }
\end{aligned}\right.
$$

where $\varphi(x)$ is the normal level set function. $a_{i}$ is an unknown of the enrichment $\mathrm{H}(\mathrm{x})$ at a node $i$, these nodes are surrounded by a square in Fig. $1 . N_{p} \subset N$ is a nodal subset of the enrichment $\beta_{\alpha}$, the tip of the crack is described by four enrichment functions [9].

$$
\left\{\beta_{\alpha}(r, \theta)\right\}=\left\{\beta_{1}, \beta_{2}, \beta_{3}, \beta 4\right\}=\left\{\sqrt{r} \sin \left(\frac{\theta}{2}\right), \sqrt{r} \cos \left(\frac{\theta}{2}\right), \sqrt{r} \sin \left(\frac{\theta}{2}\right) \sin (\theta), \sqrt{r} \cos \left(\frac{\theta}{2}\right) \sin (\theta)\right\}
$$

where $r=\sqrt{\left(\varphi^{2}+\psi^{2}\right)}$ and $\theta=\tan ^{-1}\left(\frac{\varphi}{\psi}\right)$ with $\varphi$ and $\psi$ are respectively normal and tangential level sets.

$b_{i}$ is an unknown of the enrichment $\beta_{\alpha}$ at a node $i$, these nodes are surrounded by a circle in Fig. 1.

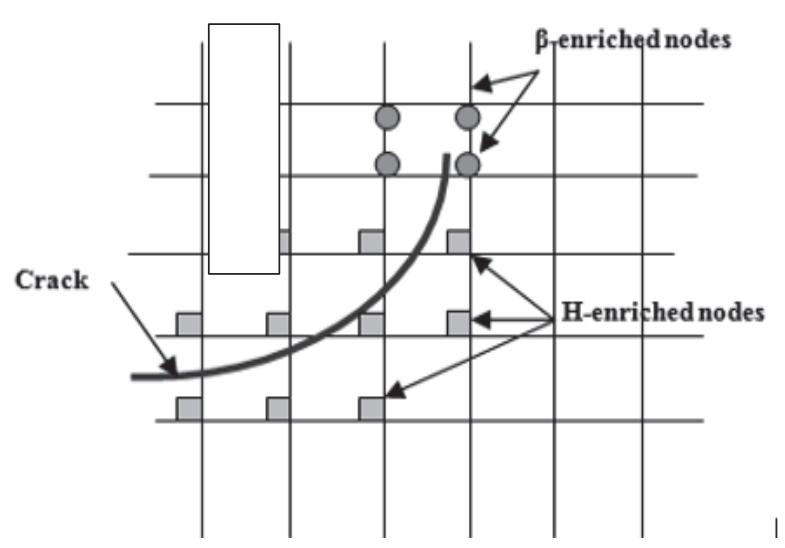

Fig. 1: The strategy of the enrichment in XFEM.

\subsection{Calculation of SIF in XFEM}

The energy release rate $G$ is the energy released for a crack advance, the G- theta is a method that calculates the $J$-integral in elastic-plastic behaviour [16]. Rice [15] showed that the J-integral can be approached by the energy release rate $\mathrm{G}$ in the elastic range.

Let I, a point in crack front $\mathrm{C}, \Gamma_{c}$ a crack surface that is composed with an outer surface $\Gamma_{c}^{+}$and an inner surface $\Gamma_{c}^{-}$. We consider $V$ a volume containing the crack front $\mathrm{C}$ (red arc in Fig. 2a) with $V=\Gamma_{c}^{+} \cup \Gamma_{c}^{-} \cup \Gamma_{0} \cup \Gamma_{1} \cup \Gamma_{2}$. For calculating the SIF in XFEM, the level sets are used as a local basis at the crack front. 


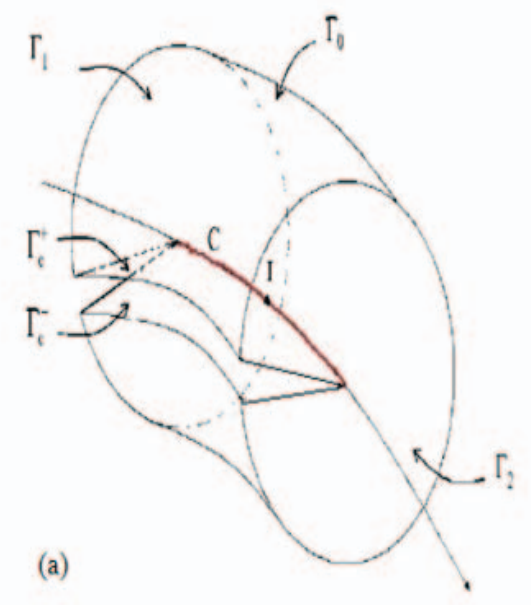

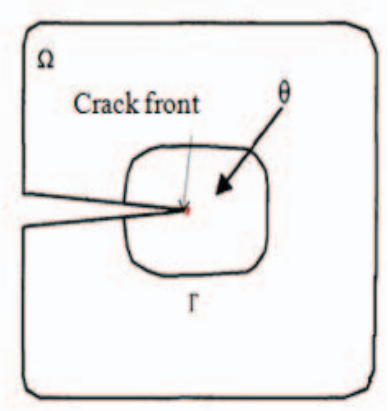

(b)

Fig. 2: (a) The domain $\mathrm{V}$ in integral $\mathrm{J}$ computation, a (b) example of $\theta$ field in 2 dimensions.

Sukumar [17] has used the gradient of the level sets, [16] has defined this local basis (Fig. 3) by $e_{1}=\nabla \psi, e_{2}=\nabla \varphi$ and $e_{3}=e_{1} \Lambda e_{2}$.

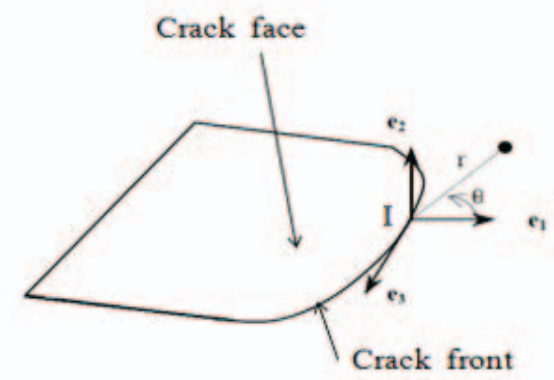

Fig. 3: The local basis on the crack front.

$J$ is expressed in a local basis (Fig. 6) formed of level set functions, $J$ is given by Eq. (4) [16]:

$J=\int_{\Gamma_{c}^{+} \cup \Gamma_{c}^{-}} \theta_{i} P_{i j} n_{j} d \Gamma-\int_{V} \theta_{i} P_{i j} d V$

where $P_{i j}$ is the Eshelby tensor [17], it is given by Eq. (5):

$P_{i j}=w \delta_{i j}-\sigma_{b j} \varepsilon_{a j} \quad(i, j, k) \in\{1,2,3\}$

where $w$ is the elastic energy density, $\sigma$ and $\varepsilon$ are respectively stress and strain expressed in the basis $\left(e_{1}, e_{2}, e_{3}\right)$ (Fig.3). $\theta$ is a field of displacement parallel to the plane of the crack and normal to the front (Fig. 2. b), it is defined by Eq. (6):

$\theta=\mu e_{1}, \mu(I)=1$ and $\mu(x)=0 \quad$ for $\quad x \in \Gamma_{0} \cup \Gamma_{1} \cup \Gamma_{2}$

For elastic behaviour of materials, $G$ is deduced from the $J$-integral by Eq. (7) [9]:

$G=\frac{E}{2\left(1-\vartheta^{2}\right)} \times \frac{J}{\int_{C} \mu d C}$ 
The SIF is deduced from $\mathrm{G}$ by Eq. (8) [9]:

$$
G=\frac{K^{2}}{E^{\prime}} \quad \text { with } E^{\prime}=\frac{E}{\left(1-\vartheta^{2}\right)} \quad \text { in plane strain }
$$

\subsection{The Meshing of the Cracked Pipe}

The cracked pipe is symmetrical, so we modelled only a half-pipe with thickness transition and an external elliptical crack (Fig. 4b), we used 3150 XFEM XC8R elements with 512 Gauss points in block crack. We used 18080 standard elements CUB8 for the rest of the mesh. The thickness transition with two slopes is generally located at the outlet of reservoirs (valves) [3], therefore in boundary conditions, we fixed the displacement of the end of the thicker part of the pipe, in addition, we blocked the translation and the rotation in $u_{y}$ and $u_{z}$ axes by applying symmetry boundary conditions (Fig. 4a). In this study, the crack is represented by level sets, we defined a normal level set from the crack front (red bow Fig. 4b) and tangential level function from the crack face.
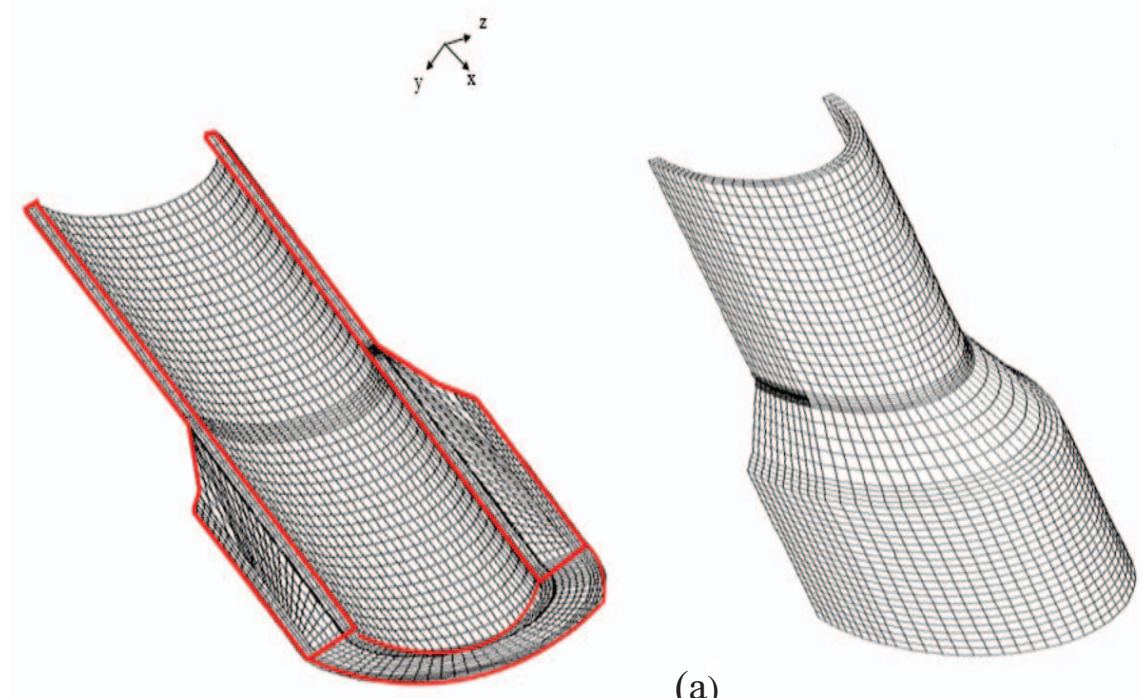

(a)

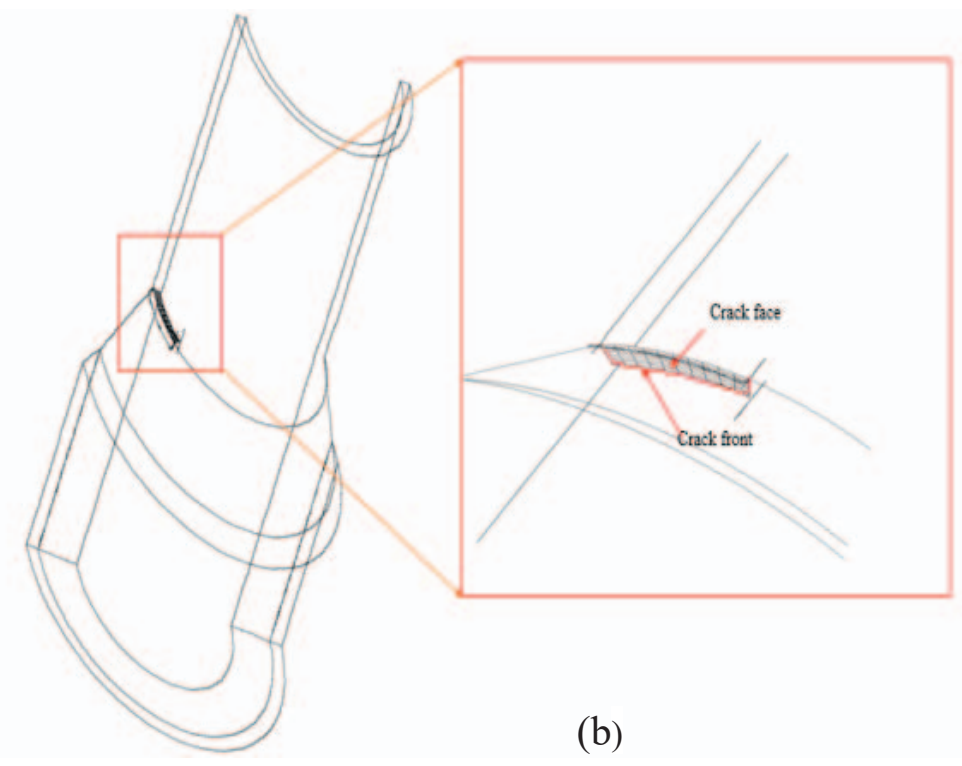

Fig. 4: (a) Cracked half -pipe with thickness transition with double slope, (b) meshing of the crack. 
The normal level set $\varphi$ (PHI) gives the distance of a point $x$ to the surface of the crack and the tangential level set $\psi$ (PSI) gives the distance of a point $\mathrm{x}$ to the crack tip, these level functions define the crack as follows: for a point $x$ of the solid (Fig. 5a):

$x \in \operatorname{crack} \Rightarrow\left\{\begin{array}{l}\varphi(x)=0 \\ \psi(x) \leq 0\end{array}\right.$ with $(|\nabla \psi|=|\nabla \varphi|=1)$

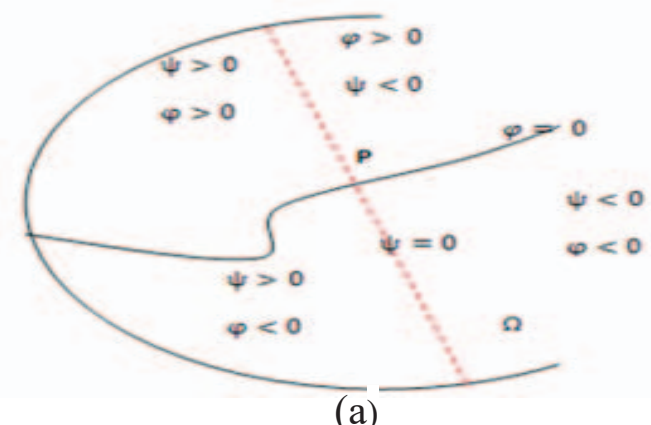

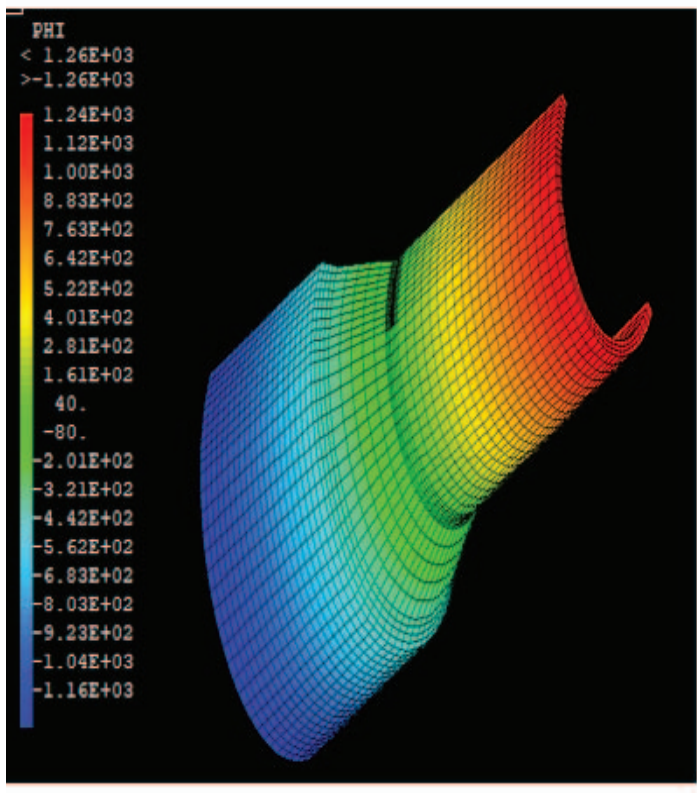

(b)
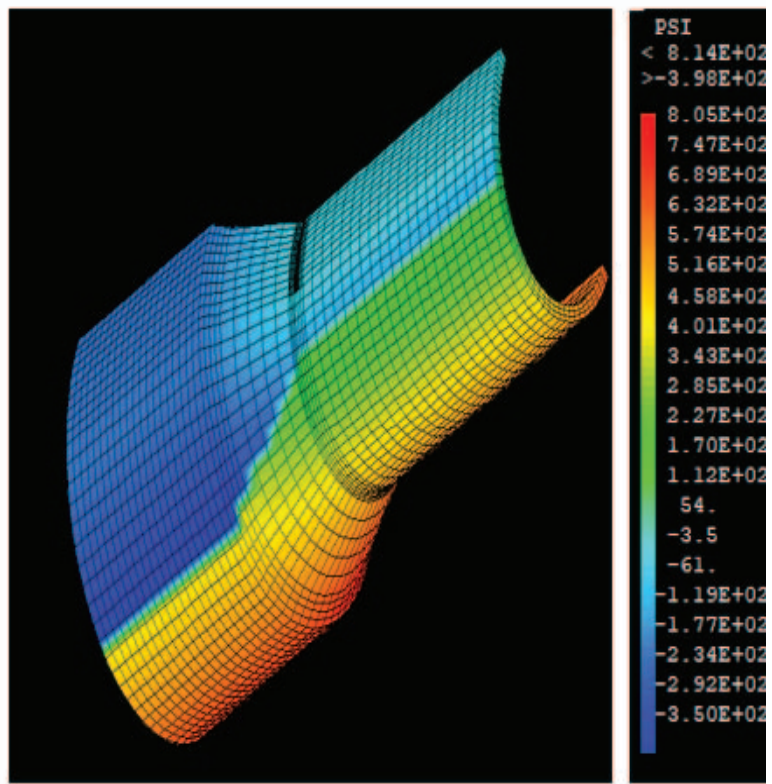

(c)

Fig. 5: (a) Representation of a crack with level sets, (b) normal level set, PHI, (c) tangential level set, PSI.

\section{GEOMETRY AND LOADING}

The study considered the elastic behaviour of the material in P265GH steel with the following properties. The geometries of the studied cracked pipes are defined by dimensionless parameters:

- A fraction of thickness $t$ on the inner radius of the pipe: $\left(t_{1} / R_{i}\right)$.

- Shape parameter defining elongation of the elliptical crack: $(\mathrm{a} / \mathrm{c})$.

- The depth of the defect standardized by the thickness of the tube: $\left(a / t_{1}\right)$.

In the present work, we model a pipe of average thickness $\left(\boldsymbol{t}_{\mathbf{1}} / R_{i}=0.1\right)$, the parameter $(\mathrm{a} / \mathrm{c})$ takes values $1,1 / 2,1 / 4$, and $1 / 8,\left(a / t_{1}\right)$ takes values $0.1,0.2,0.4,0.6,0.8$. This gives a set of 20 geometries. 
Table 1: Properties of P265GH steel

\begin{tabular}{ccccc}
\hline $\begin{array}{c}\text { Young's modulus, } \\
\mathbf{E},(M P a)\end{array}$ & Yield stress, $\sigma,(M P a)$ & $\begin{array}{c}\text { Poisson's } \\
\text { ratio, } \vartheta\end{array}$ & $\begin{array}{c}\text { Breaking stress, } \\
\sigma_{u},(M P a)\end{array}$ & $\begin{array}{c}\text { Nominal stress, } \\
f,(M P a)\end{array}$ \\
\hline 200000 & 320 & 0.3 & 470 & 148 \\
\hline
\end{tabular}

Elliptical cracks are considered to be located at the base of the transition in the thin part of the pipe (Figs. 4 and 6).

The study considered pipe with thickness transition with a single slope $\left(\boldsymbol{t}_{\mathbf{1}}, \boldsymbol{t}_{\mathbf{2}}, \boldsymbol{\alpha}_{\mathbf{1}}\right)$ and thickness transition with double slopes $\left(\boldsymbol{t}_{1}, \boldsymbol{t}_{2}, \boldsymbol{t}_{3}, \boldsymbol{\alpha}_{1}, \boldsymbol{\alpha}_{2}\right)$ (Fig. 6). Pressurized pipe with thickness transition is a connection between pipe of thickness $\boldsymbol{t}_{\mathbf{1}}$ assembled to another pipe of a thickness $t_{2}$ and $t_{3}\left(t_{3}>t_{2}>t_{1}\right)$.

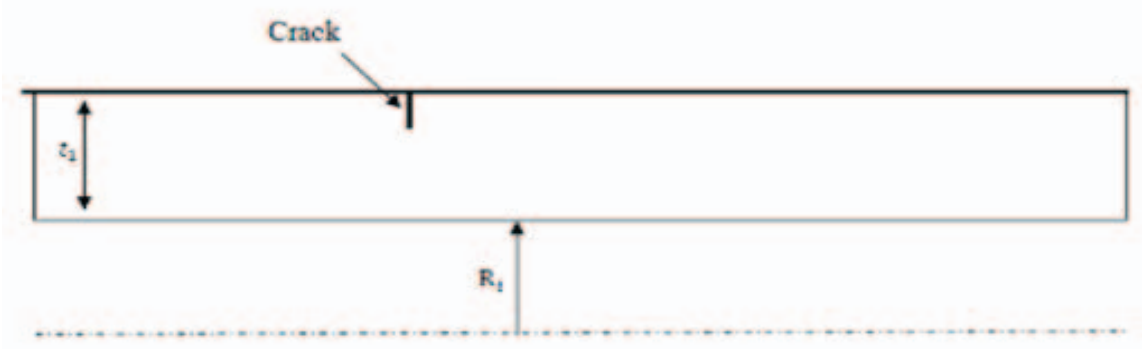

(a)

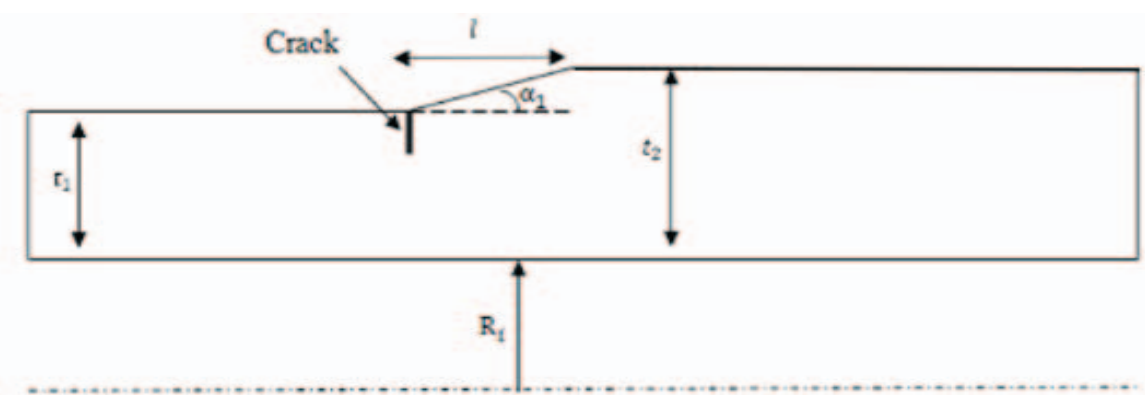

(b)

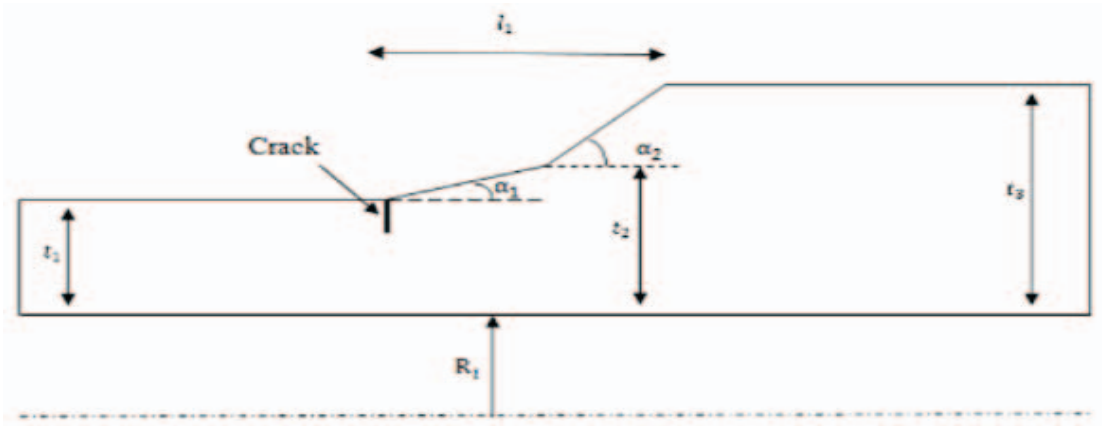

(c)

Fig. 6: Geometry of different types of pipes: (a) straight pipe, (b) pipe with thickness transition (single slope), (c) pipe with thickness transition (double slope).

$\boldsymbol{t}_{\boldsymbol{j}}$ is the thickness of the pipe, with $\mathrm{j} \in\{1,2,3\} .\left(\alpha_{j}\right)$ is the slope of a thickness transition in a pipe with $\mathrm{j} \epsilon\{1,2\}$. SIF, $(\mathrm{K})$ is the stress intensity factor. The purpose of this study is 
the investigation of the impact of $\boldsymbol{t}_{\boldsymbol{j}}$ and $\left(\alpha_{j}\right)$ on the stress intensity in a pipe with thickness transition. So, we consider $\boldsymbol{t}_{\boldsymbol{j}}$ and $\left(\alpha_{j}\right)$ as variable parameters, and analyse their effect on SIF.

Pipes are subjected to an internal pressure P (Fig. 7), for the purpose of comparison with the straight cylinder, the internal pressure is calculated in the thin part (thickness $t_{1}$ ) of the pipe with thickness transition, $\mathrm{P}$ is calculated according to the CODAP (C2.1.4.2) instructions [18]:

$$
P=\frac{2 \times f \times t_{1} \times z}{D_{m}}
$$

where $\mathrm{z}$ is the welding coefficient. $D_{m}=\mathrm{R}_{\mathrm{e}}+R_{i}$ is the inner diameter of the pipe. $R_{i}$ and $\mathrm{R}_{\mathrm{e}}$ are respectively inner and outer radius of thin pipe where $\mathrm{R}_{\mathrm{e}}=t_{1}+R_{i}$. So, Eq. (10) becomes:

$$
P\left(\frac{R_{i}}{t_{1}}\right)=\frac{2 f}{2\left(\frac{R_{i}}{t_{1}}\right)+1} \text { with } \frac{R_{i}}{t_{1}}=10
$$

The internal pressure is $\mathrm{P}=14 \mathrm{MPa}$, this pressure does not cause general plastic behaviour in the pipe of an average thickness $\left(t_{1} / R_{i}=0.1\right)$.

(a)
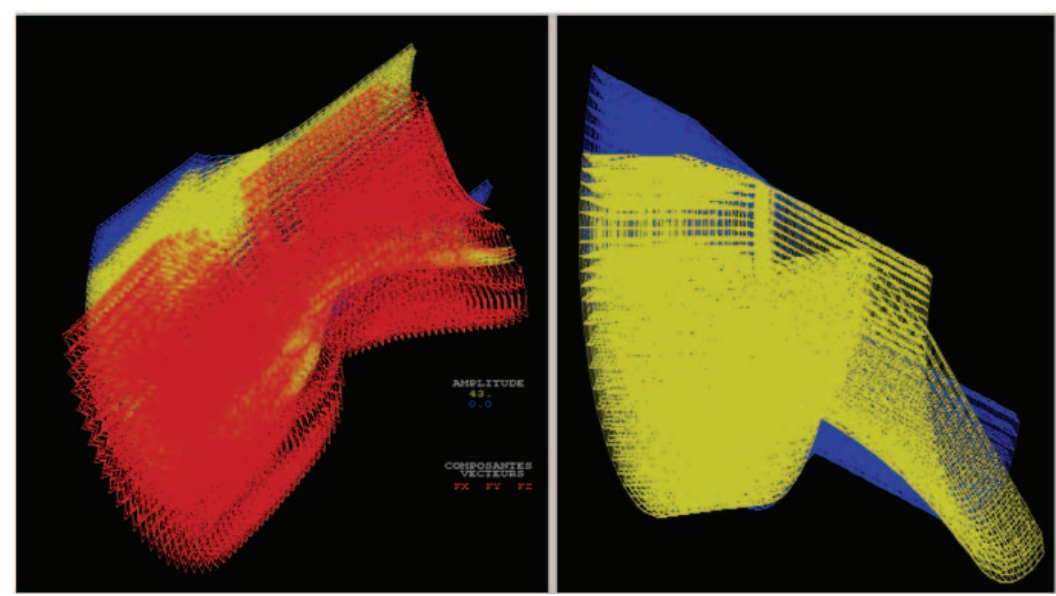

(b)
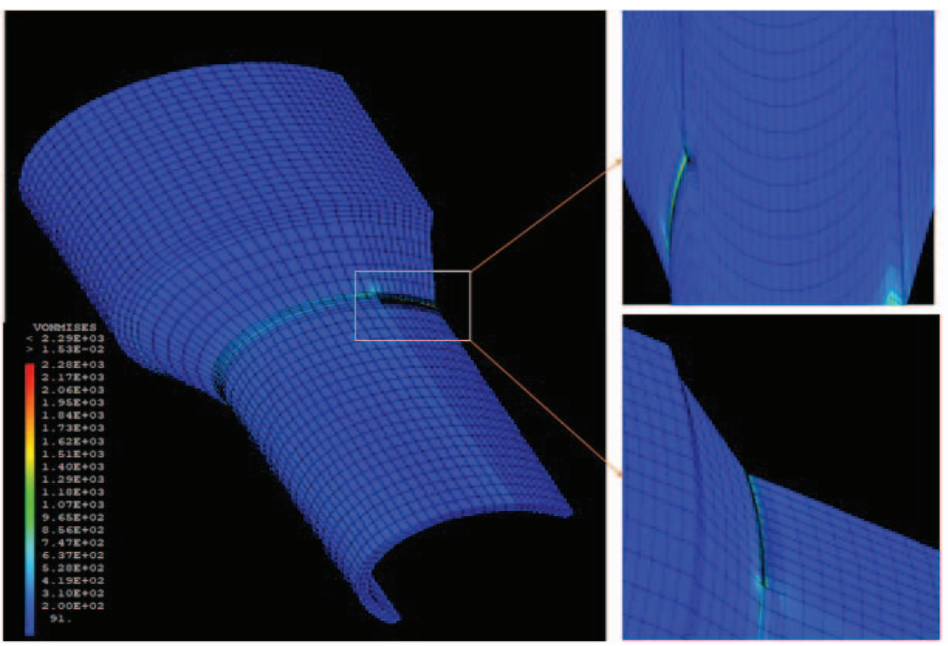

Fig. 7: Pipe with thickness transition: (a) subjected to internal pressure, (b) Von Mises stress. 


\section{RESULTS AND DISCUSSION}

\subsection{Verification of the XFEM model}

The Castem 2016 software [7] was used for modelling and calculation; it has XFEM and G-Theta capabilities. The position of a point $\mathrm{P}$ on the crack front is defined by the angle $\phi\left(^{\circ}\right.$ ) (Fig. 8), $\phi$ takes the value of $90^{\circ}$ at the deepest point (D point) and $0^{\circ}$ at the surface point (S point), those two points characterize the semi-elliptical crack. In general, the evaluation of SIF at those two points is enough to judge the severity of the defect. At those points, the average value of $\mathrm{K}$ is given by Eqs. (12) and (13) [8]:

$$
\begin{aligned}
& K_{\text {average }}=\frac{1}{5}\left(4 K_{p o \text { int } 2}+K_{p o \text { int } 3}\right) \text { in D point } \\
& K_{\text {average }}=\frac{1}{6}\left(K_{p o i n t 4}+4 K_{p o \text { int } 5}+K_{p o \text { int } 6}\right) \text { in } S \text { point }
\end{aligned}
$$

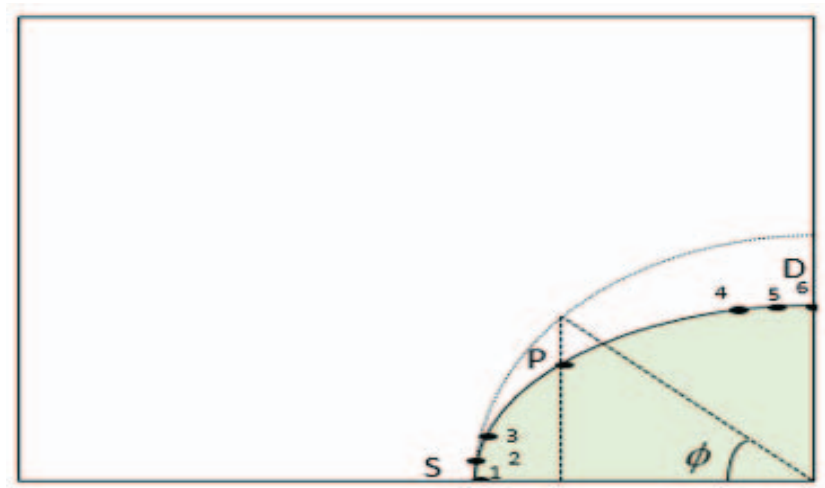

Fig. 8: Definition of average values on the element [8].

The French Alternative Energies and Atomic Energy (CEA) [6] studied straight pipes containing external circumferential cracks, CEA [8] calculated the influence factor $\left(i_{0}\right)$ using the finite element method (FEM).

$i_{0}=\frac{K}{\frac{P R_{i}^{2}}{\left(R_{e}^{2}-R_{i}^{2}\right)} \sqrt{\pi a}} \quad$ for an external circumferential crack

where $\mathrm{P}$ is the pressure calculated in Eq. (10) and $\mathrm{K}$ is the SIF calculated by the $\mathrm{G}-$ Theta method in XFEM. The verification of the model was made by the comparison of the values $i_{0}$ calculated by XFEM in the present paper and the results of CEA [8]. The relative error was calculated according to the Eq. (15):

$e_{1}=100 \times\left|\frac{\left(i_{0_{C E A}}-i_{0_{X F E M}}\right)}{i_{0_{C E A}}}\right|$

$i_{\mathrm{O}}$ is calculated at $\mathrm{D}$ and $\mathrm{S}$ points and along the crack front (Fig. 8) for all fractions $\left(\mathrm{a} / t_{1}\right)$ and $(\mathrm{a} / \mathrm{c})$, a sample of the results is presented in Figs. 9-11. The relative error between the XFEM results and literature [8] is between $0.09 \%$ and $0.7 \%$. This gives confirmation to use numerical simulation based on XFEM to investigate the SIF at a thickness transition with one and two slopes in pressurized pipe. 


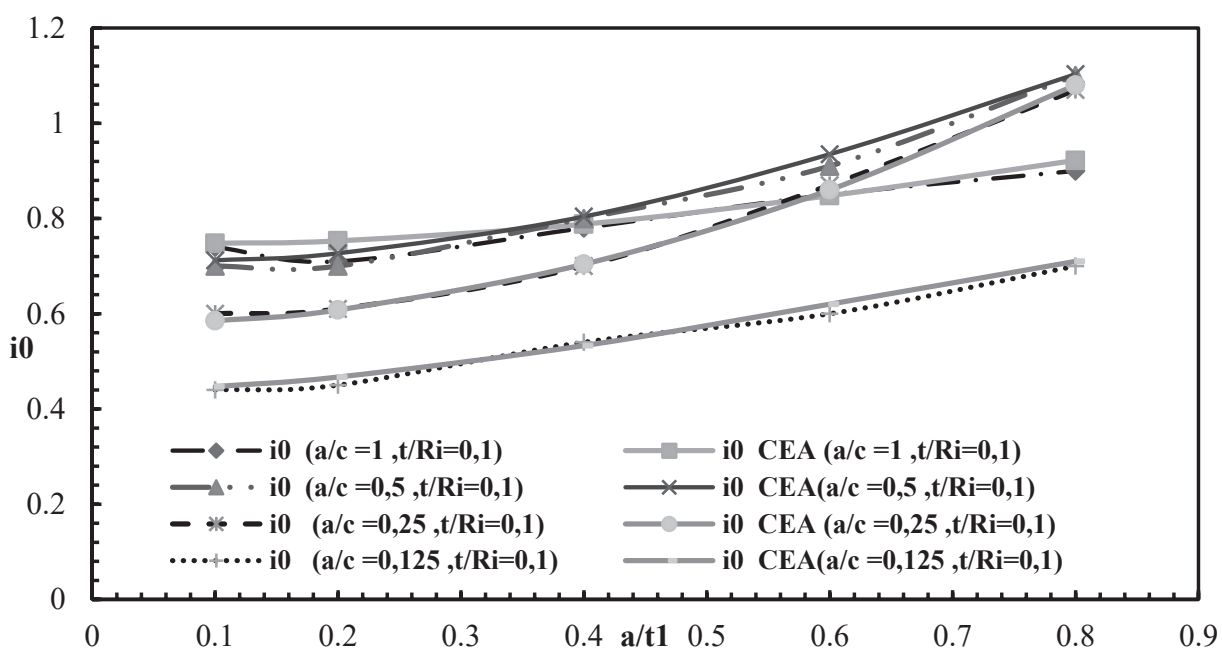

Fig. 9: Comparisons of $i_{0}$ calculated by XFEM in the present study with the literature [8], at S point, $t_{1} / R_{i}=0.1$.

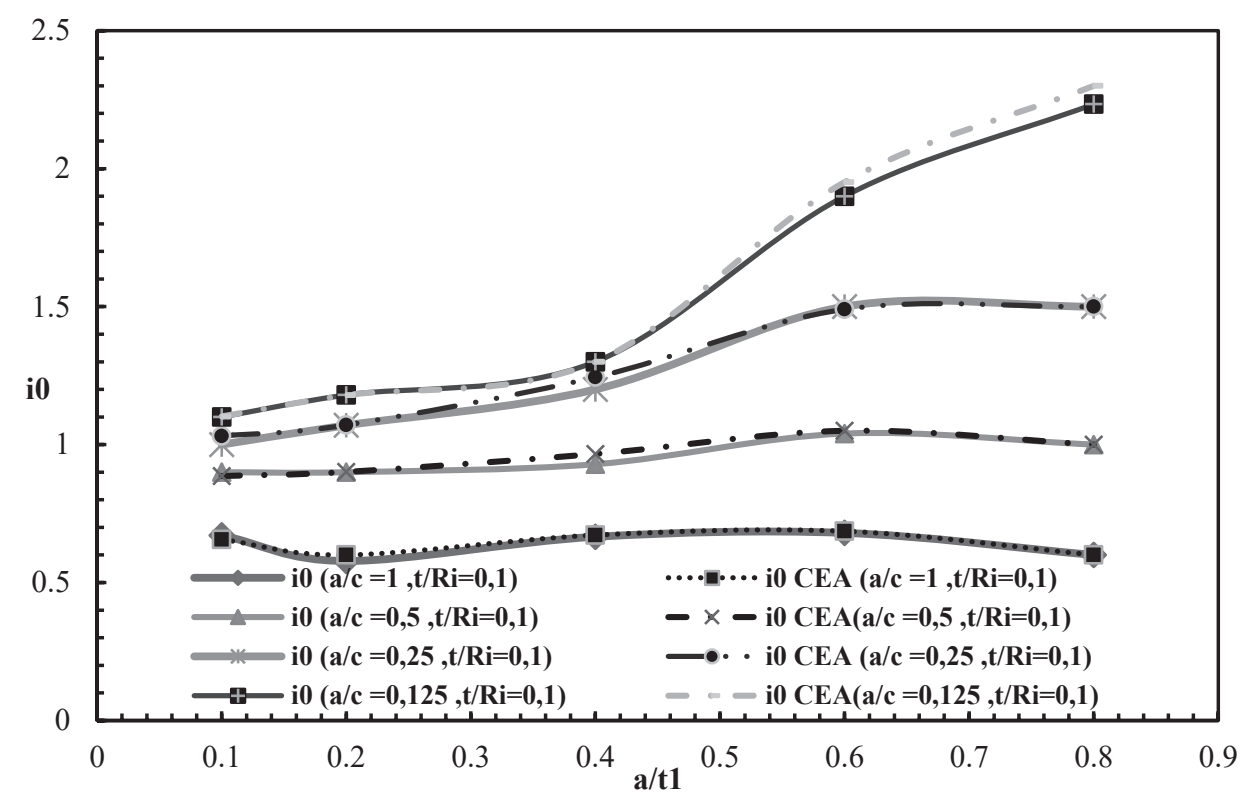

Fig. 10: Comparisons of $i_{0}$ calculated by XFEM in the present study with the literature [8], at D point, $t_{1} / R_{i}=0.1$.

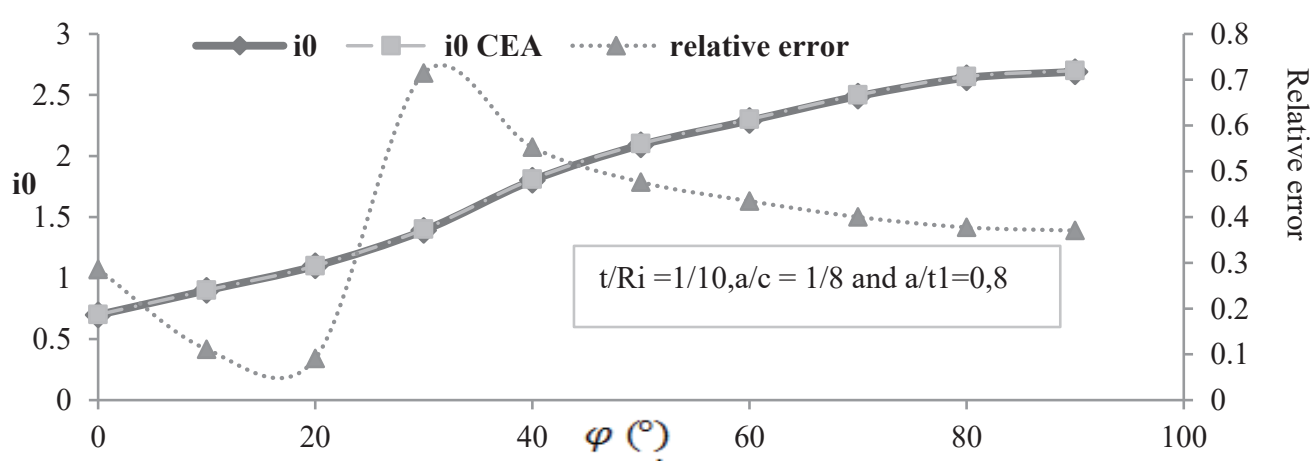

Fig. 11: Comparisons of $i_{0}$ calculated by XFEM in the present study with the literature [8], along the crack front. 


\subsection{Comparison between $K$ of the Pipe with Uniform Thickness and the Pipe with Thickness Transition}

In a previous paper, we analysed the effect of cracks in the thickness transition zone of pressurized pipes using XFEM [19,20]. We have considered the elastic behaviour of the material and thickness transition with a single slope. The calculations of $\mathrm{K}$ for different geometries of the pipe subjected to internal pressure showed that cracks in the transition are the most severe. This result is in concordance with [3] which considered tensile stress and a bending moment. The present paper extends the previous work to the case of thickness transition with two slopes.

Figures 12 and 13 present the evolution of $\mathrm{K}$ value according to $\mathrm{a} / t_{1}$ in deepest and surface points in case of $t_{1} / R_{i}=0.1$, for three types of pipes: uniform thickness, thickness transition with one slope, thickness transition with two slopes.

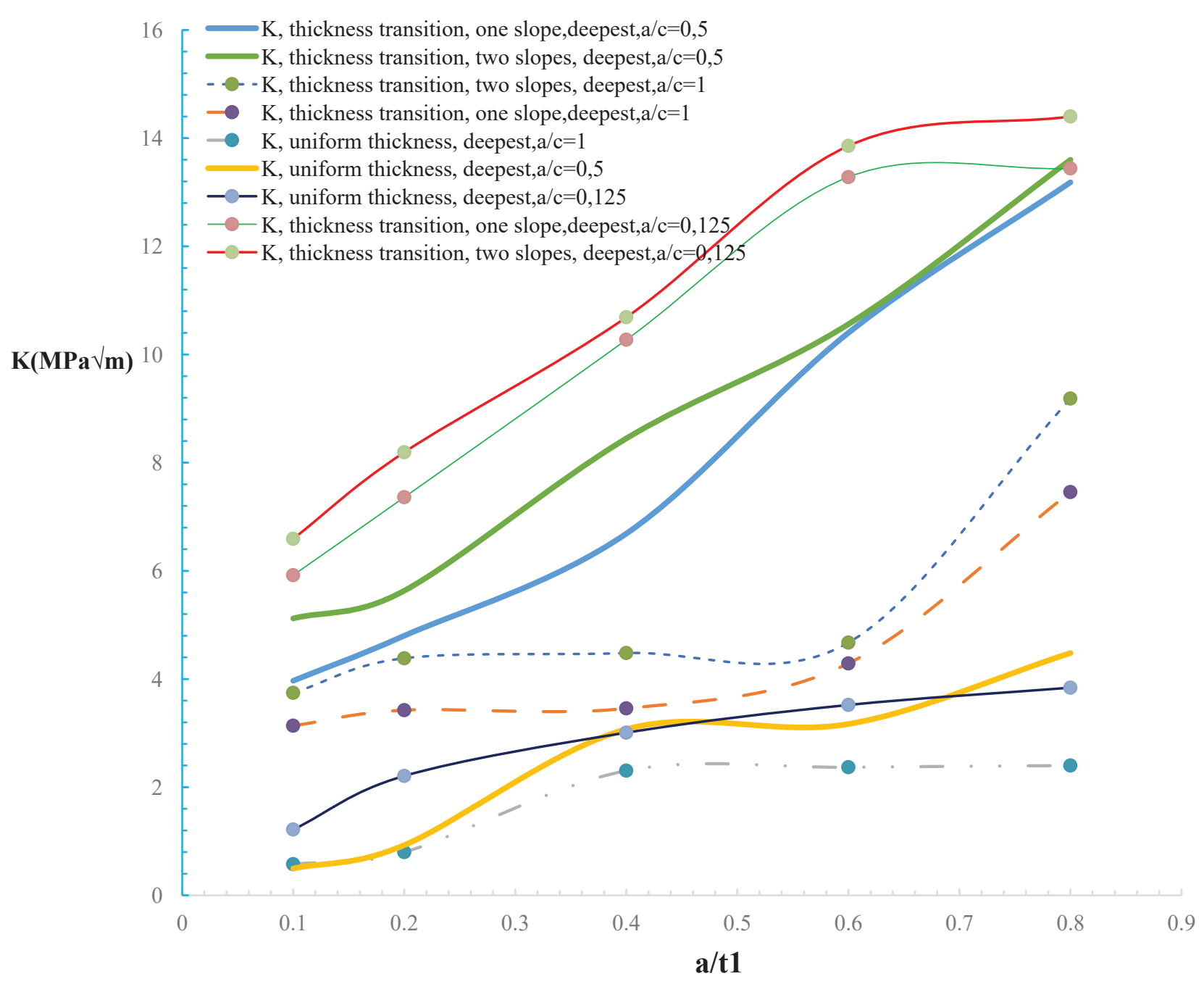

Fig. 12: Evolution of $\mathrm{K}$ value according to a/t for pipes: uniform thickness, transition thickness with one slope, transition thickness with one slope, D point, $t_{1} / R_{i}=0.1$, internal pressure. 


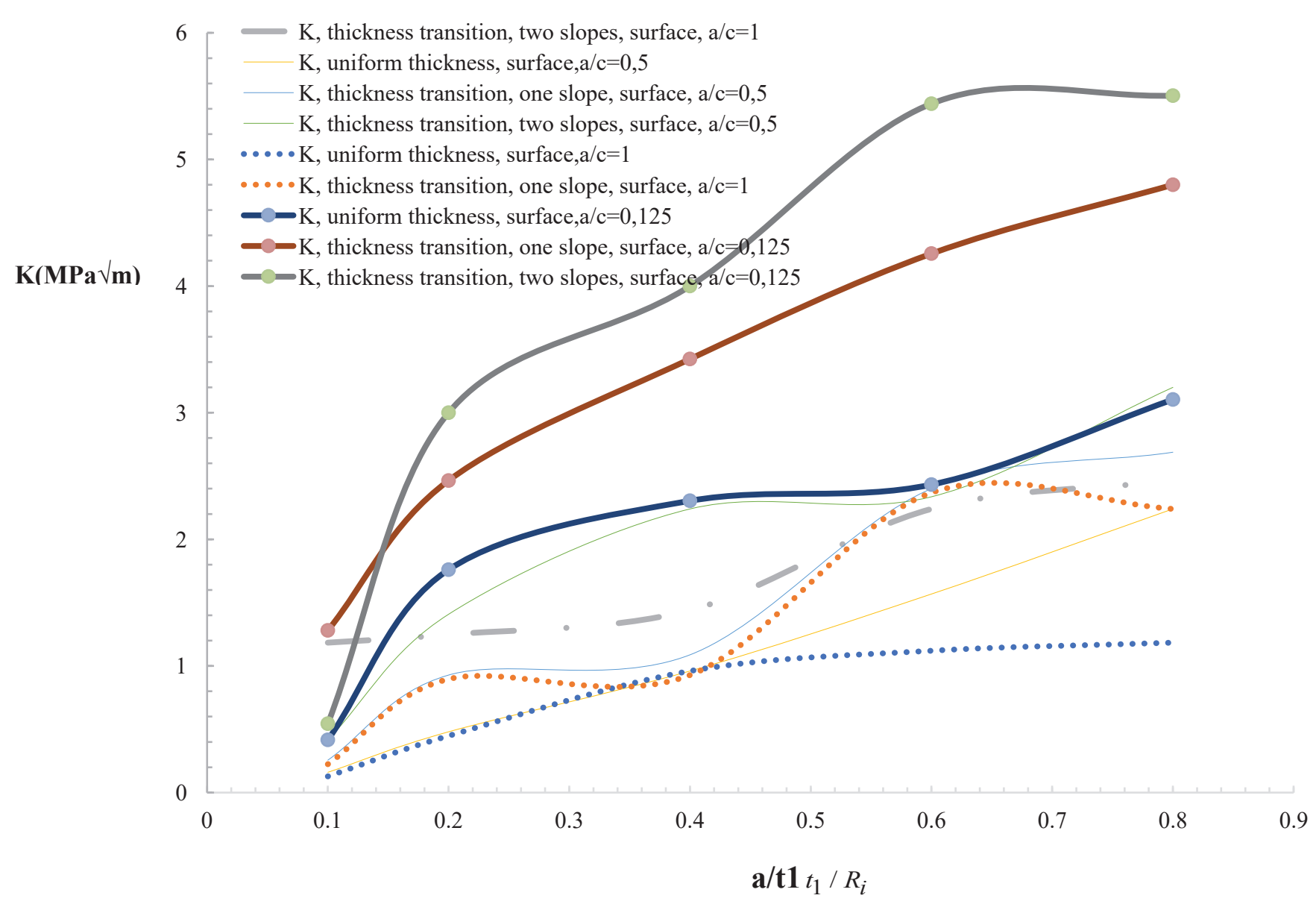

Fig. 13: Evolution of $\mathrm{K}$ value according to $\mathrm{a} / \boldsymbol{t}_{\mathbf{1}}$ for pipes: uniform thickness, transition thickness with one slope, transition thickness with one slope, $\mathrm{S}$ point, $t_{1} / R_{i}=0.1$, internal pressure.

The results show that for the deepest point we have:

- $\mathrm{K}$ increases when $a / t_{1}$ increases for all types of pipe that to say $\mathrm{K}$ is higher for depth crack $\left(a / t_{1}=0.8\right)$ for all pipes with different thicknesses and slopes.

- $\mathrm{K}$ is sensitive to the parameter $\mathrm{a} / \mathrm{c}, \mathrm{K}$ increases when $\mathrm{a} / \mathrm{c}$ decreases for all depths of the crack $\left(a / t_{1}\right)$, that's to say $\mathrm{K}$ is higher $(14 \mathrm{MPa})$ for longer crack $(\mathrm{a} / \mathrm{c}=0.125)$.

- $\mathrm{K}$ is high for pipe with thickness transition, at the same time thickness transition with two slopes have the highest $\mathrm{K}$ for all forms of cracks.

The results show that for the surface point we have:

- $\mathrm{K}$ depends on the parameter $\mathrm{a} / \mathrm{t}$ for different pipes

- K varies slightly when $\mathrm{a} / \mathrm{c}$ decreases for all depths of the crack $\left(a / t_{1}\right)$, for a/c $=0.125 \mathrm{~K}$ attain only $5 \mathrm{MPa}$.

As a result, in the case of a pipe with an average thickness $\left(t_{1} / R_{i}=0.1\right)$, for a fixed angle $\alpha_{1}=30^{\circ}$ and $\alpha_{2}=45^{\circ}$, we found that the thickness transition with two slopes has the greatest value of $\mathrm{K}$, so it presents the greatest risk compared to the straight pipe and pipe with thickness transition and a single slope. 
Do these values of $\alpha_{1}=30^{\circ}$ and $\alpha_{2}=45^{\circ}$, lead to a greater value of $\mathrm{K}$ ? How does the variation of the parameters $\alpha_{1}, \alpha_{2}$ and $t_{j}$ ( $\left.\mathrm{j} \epsilon\{1,2,3\}\right)$ influence the variations of $\mathrm{K}$ for a pipe with average thickness?

\subsection{Effect of the Transition Zone on the Variation of $\mathrm{K}$}

Based on the triangular relation, the length of the thickness transition is related to the angle of the slope by the following relation:

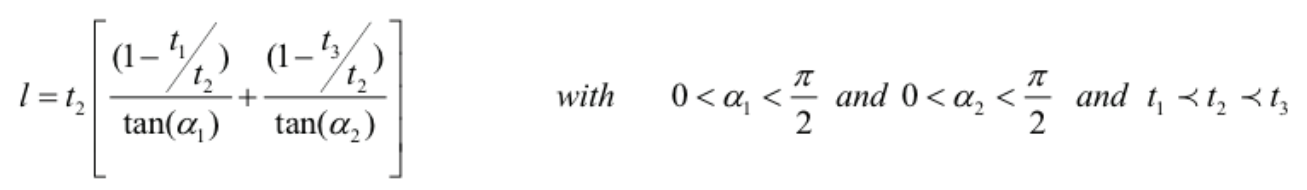

(l) mainly depends on $\left(t_{2} / t_{1}\right),\left(t_{3} / t_{2}\right), \boldsymbol{\alpha}_{1}$ and $\boldsymbol{\alpha}_{2}$. We consider those parameters as variable and analyze their effect on the variation of $K$.

\subsubsection{Effect of the Slope in Thickness Transition on the Variation of $K$}

In this study, we considered a pipe with an average thickness where $\left(t_{2} / t_{1}\right)=\left(t_{3} / t_{2}\right)$ $=2.5$, the pipe contained an elliptical crack defined by $\mathrm{a} / \mathrm{c}=0.125$ and $\mathrm{a} / t_{1}=0.8$, the pipe is exposed to internal pressure. Figure 14 (a) presents the evolution of $\mathrm{K}$ according to $\boldsymbol{\alpha}_{1}$ for a fixed value of $\boldsymbol{\alpha}_{2}$ in a deepest and surface points.

The result shows that $\mathrm{K}$ increases when $\boldsymbol{\alpha}_{1}$ increases, $\mathrm{K}$ attains the maximum $\left(K_{\text {deepest point }}=55 \mathrm{MPa}\right)$ for $\boldsymbol{\alpha}_{1}=30^{\circ}$. For $\boldsymbol{\alpha}_{1}>30^{\circ}, \mathrm{K}$ decreases and tends to stabilize to equal a great value compared with the value of K when $\alpha_{1}<30^{\circ}$.

$\mathrm{K}$ in deepest point is higher than $\mathrm{K}$ in surface point for $20^{\circ}<\boldsymbol{\alpha}_{1}<50^{\circ}$ but for $\boldsymbol{\alpha}_{1}>$ $50^{\circ} K_{\text {surface point }}$ exceeds $K_{\text {deepest point }}$. The transition reacts as an amplifier of stress, it magnifies the stress close to the surface, so the value of $\mathrm{K}$ is higher for the great value of $\boldsymbol{\alpha}_{1}\left(\boldsymbol{\alpha}_{1}>50^{\circ}\right)$ of the slope of the first transition ( ${ }_{2}$ is fixed). When $\boldsymbol{\alpha}_{1}$ decreases $\left(\alpha_{1}<50^{\circ}\right)$, the concentration of the stress decreases at S point, because at S point, the thickness transition impact noticeably reduces in comparison with the effect of internal pressure which increases the concentration of stress in the deepest point. Therefore, the value of $\mathrm{K}$ at $\mathrm{D}$ point becomes higher compared to the value of $\mathrm{K}$ in the surface point for small values of $\boldsymbol{\alpha}_{1}$.

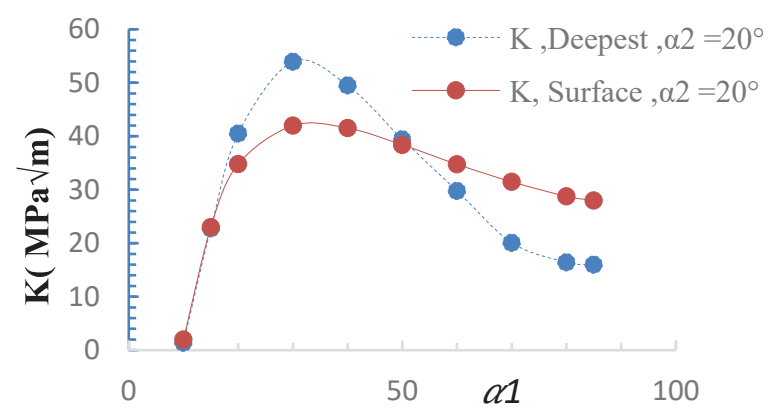

(a)

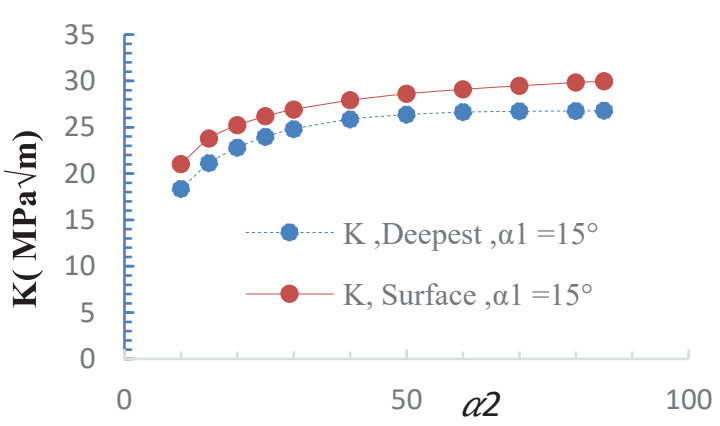

(b)

Fig. 14: Variation of $\mathrm{K}$ at deepest and surface points:

(a) According to $\alpha_{1}$, (b) According to $\alpha_{2}$.

Figure 14 (b) presents the evolution of $\mathrm{K}$ according to $\boldsymbol{\alpha}_{2}$ for a fixed value of $\boldsymbol{\alpha}_{1}$ in deepest and surface points. The result shows that $\mathrm{K}$ increases in a weak way, when $\boldsymbol{\alpha}_{2}$ 
increases and it attains the maximum $\left(K_{\text {surface point }}=29 \mathrm{MPa}\right)$ for $\boldsymbol{\alpha}_{2}=45^{\circ}$. For $\boldsymbol{\alpha}_{2}>$ $45^{\circ}, \mathrm{K}$ keeps a stable value, At the same time, the values of $\mathrm{K}$ at the deepest point are close to those of $\mathrm{K}$ at the surface point for all values of $\boldsymbol{\alpha}_{2}$, that's to say the angle of the slope $\boldsymbol{\alpha}_{2}$ does not have a great effect on the variation of K.

As a result, the slopes $\boldsymbol{\alpha}_{1} \geq 30^{\circ}$ and $\boldsymbol{\alpha}_{2} \geq 45^{\circ}$ present a grave case for thickness transition with a double slope, also the angle of the first slope $\left(\boldsymbol{\alpha}_{1}\right)$ in thickness transition has more impact on the variations of $\mathrm{K}$ than the angle of the second slope $\left(\boldsymbol{\alpha}_{2}\right)$.

\subsubsection{Effect of Parameters $\left(\alpha_{1},\left(t_{2} / t_{1}\right)\right)$ and $\left(\alpha_{1},\left(t_{3} / t_{2}\right)\right)$ on the Variation of $K$ in Thickness Transition with a Double Slope}

In the part (4.3.1), we supposed $\boldsymbol{\alpha}_{1}$ and $\boldsymbol{\alpha}_{2}$ as variables and analyzed their effect on the variation of $K$ in thickness transition for fixed values of $\left(t_{2} / t_{1}\right)$ and $\left(t_{3} / t_{2}\right)$. In this part, firstly, we consider $\boldsymbol{\alpha}_{1}$ and $\left(t_{2} / t_{1}\right)$ as variables and we fix $\left(t_{3} / t_{2}\right)$ and $\boldsymbol{\alpha}_{2}$, in this case, the parameter $\boldsymbol{\alpha}_{1}$ is varied within the range of $5^{\circ}$ to $50^{\circ}$ and the ratio $\left(t_{2} / t_{1}\right)$ is varied from 1.1 to 6 , secondly, we vary $\boldsymbol{\alpha}_{1}$ and $\left(t_{3} / t_{2}\right)$ and fix other parameters, the ratio $\left(t_{3} / t_{2}\right)$ is varied from 1.1 to 4 .

Figure $15 \mathrm{a}-\mathrm{b}$ present the variations of $\mathrm{K}$ according to the parameters $\boldsymbol{\alpha}_{1}$ and $\left(t_{2} / t_{1}\right)$, for $\left(t_{3} / t_{2}\right)=1.30$ and $\boldsymbol{\alpha}_{2}=30^{\circ}$ at deepest and surface points. Figure 15a-b, show that for both $\mathrm{D}$ and $\mathrm{S}$ points, we have:

- For $1.1 \leq\left(t_{2} / t_{1}\right) \leq 1.5$, the value of $\mathrm{K}$ is high and exceeds the toughness of materials P265GH $\left(K_{C}=96 \mathrm{MPa} \sqrt{m}\right)$.

- For all values of $\boldsymbol{\alpha}_{1}$, in the case of $1.5<\left(t_{2} / t_{1}\right)$, we note that $\mathrm{K}$ decreases when $\left(t_{2} / t_{1}\right)$ increases and stabilizes for $\left(t_{2} / t_{1}\right)$ greater than 4.5 .

- For $\boldsymbol{\alpha}_{1} \geq 30^{\circ}, \mathrm{K}$ takes the greatest value for all $\left(t_{2} / t_{1}\right)$.

As a result, the great value of the angle of the first slope in a cracked pipe has an important effect on the variation of $\mathrm{K}$, more precisely $\boldsymbol{\alpha}_{1} \geq 30^{\circ}$ is a grave case for the construction of the pipe and increasing the ratio of thicknesses $\left(t_{2} / t_{1}\right)$, is an effective way to reduce the risk of the defect in a pipe.

Figure $15 \mathrm{c}-\mathrm{d}$ present the variations of $\mathrm{K}$ according to the parameters $\boldsymbol{\alpha}_{1}$ and $\left(t_{3} / t_{2}\right)$, for $\left(t_{2} / t_{1}\right)=1.40$ and $\boldsymbol{\alpha}_{2}=30^{\circ}$ at deepest and surface points. The curves of stress intensity show that for $\mathrm{D}$ and $\mathrm{S}$ points, we have:

- In the case of $\boldsymbol{\alpha}_{1} \geq 30^{\circ} ; \mathrm{K}$ exceeds the toughness of materials $\left(K_{C}\right)$, K decreases when $\left(t_{3} / t_{2}\right)$ increases.

- In the case of $\boldsymbol{\alpha}_{1}<30^{\circ} ; \mathrm{K}$ increases when $\left(t_{3} / t_{2}\right)$ increases but it but this evolution of $\mathrm{K}$ as a function of ratio $\left(t_{3} / t_{2}\right)$ is not remarkable.

As a result, the parameter $\left(t_{3} / t_{2}\right)$ does not have more impact on the variation of $\mathrm{K}$ in thickness transition with a double slope for a pressurized pipe.

\subsubsection{Effect of Parameters $\left(\alpha_{2},\left(t_{2} / t_{1}\right)\right)$ and $\left(\alpha_{2},\left(t_{3} / t_{2}\right)\right)$ on the Variation of $K$ in Thickness Transition with a Double Slope}

Proceeding as before; we analysed the evolution of $\mathrm{K}$ in the thickness transition by fixing two parameters of the transition zone and varying the rest. 


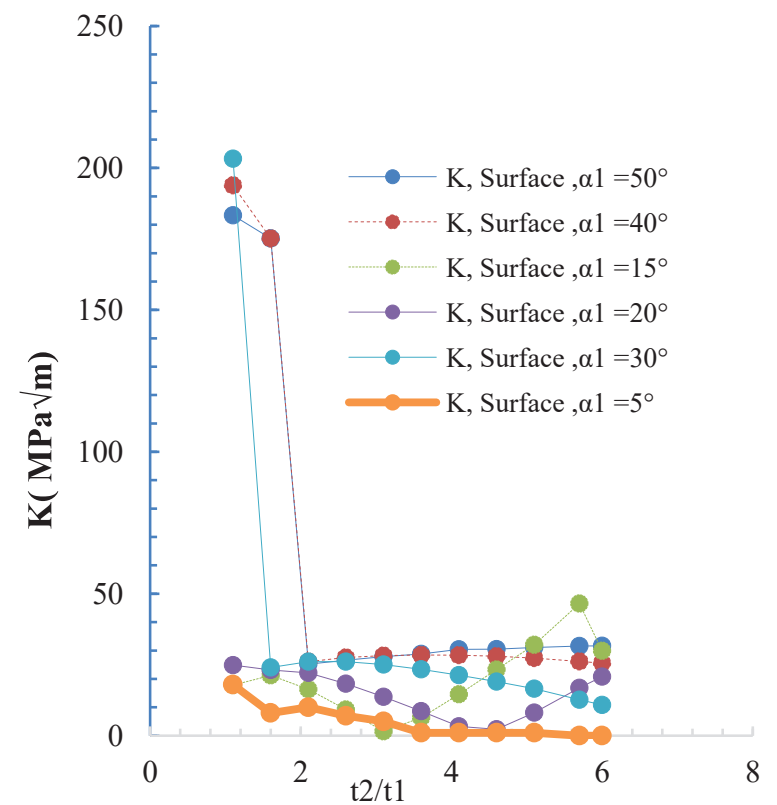

(a)

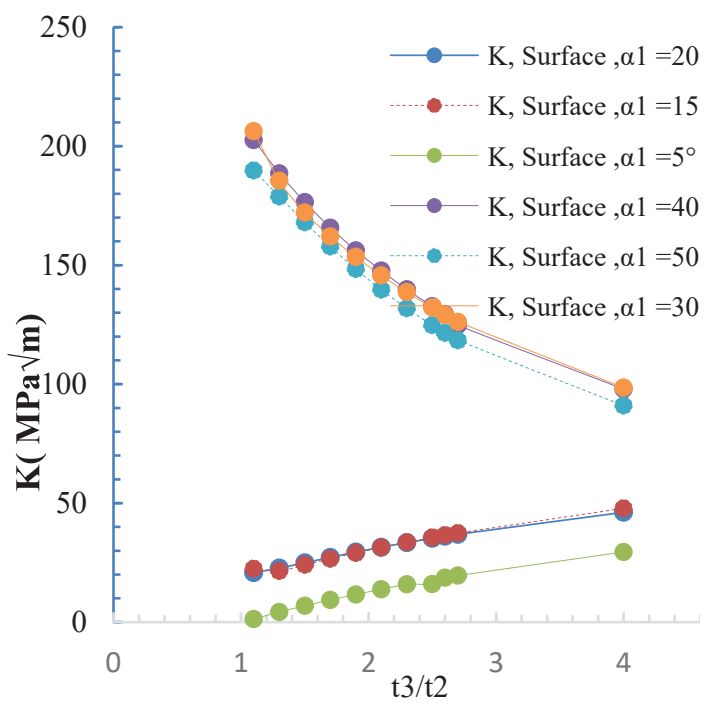

(c)

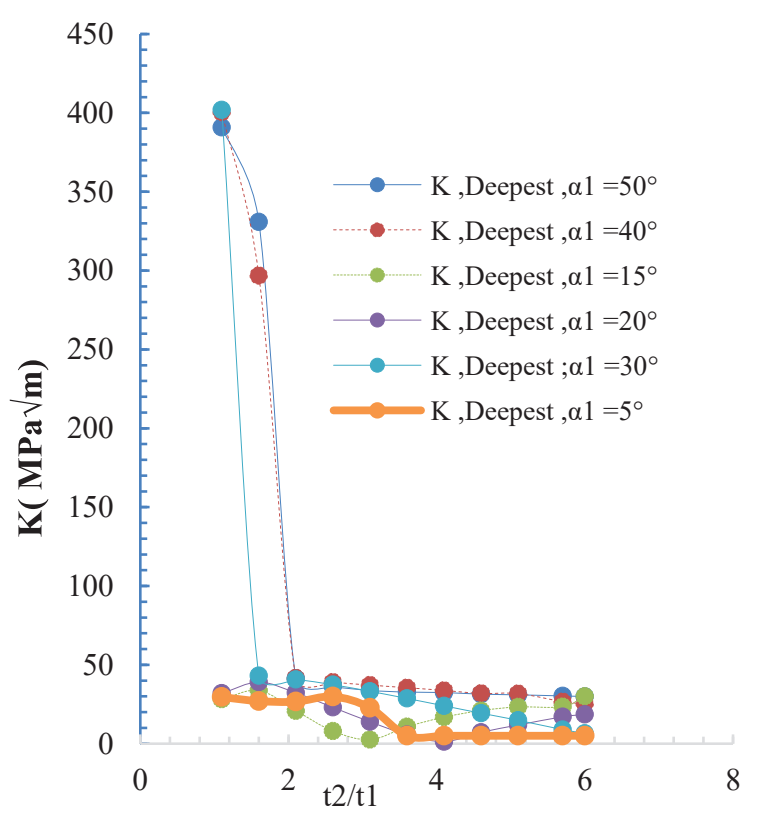

(b)

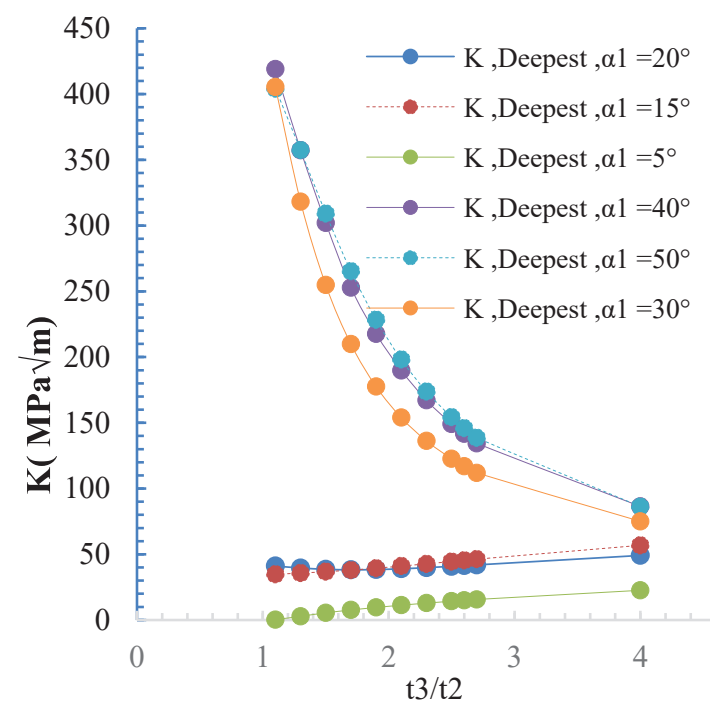

(d)

Fig. 15: Variation of $\mathrm{K}$ at deepest and surface points:

(a-b), according to $\alpha_{1}$ and $\left(t_{2} / t_{1}\right)$, (c-d), according to $\alpha_{1}$ and $\left(t_{3} / t_{2}\right)$.

Figure 16a-b present the variations of $\mathrm{K}$ according to the parameters $\boldsymbol{\alpha}_{2}$ and $\left(t_{2} / t_{1}\right)$, for $\left(t_{3} / t_{2}\right)=1.30$ and $\boldsymbol{\alpha}_{1}=20^{\circ}$ at deepest and surface points. The parameter $\boldsymbol{\alpha}_{2}$ is varied within the range of $10^{\circ}$ to $50^{\circ}$ and the ratio $\left(t_{2} / t_{1}\right)$ is varied from 1.1 to 6 . The result shows that the stress intensity curves don't depend on the variation of $\boldsymbol{\alpha}_{2}$ for $\mathrm{S}$ and D points. The variation of $\mathrm{K}$ relates mostly on the parameter $\left(t_{2} / t_{1}\right)$ of the first thickness transition, the range $3.5 \leq\left(t_{2} / t_{1}\right) \leq 4$ allows small values of $\mathrm{K}(\mathrm{K}<9 \mathrm{MPa})$.

Figure 16c-d present the variations of K according to the parameters $\boldsymbol{\alpha}_{2}$ and $\left(t_{3} / t_{2}\right)$, for $\left(t_{2} / t_{1}\right)=1.40$ and $\boldsymbol{\alpha}_{1}=20^{\circ}$ at deepest and surface points. The ratio $\left(t_{2} / t_{1}\right)$ is varied 
from 1.1 to 4.5 . The results show again, that $\boldsymbol{\alpha}_{2}$ does not have enough effect on the variation of $\mathrm{K}$, in addition, $\mathrm{K}$ increa,ses when $\left(t_{2} / t_{1}\right)$ increases but this variation of $\mathrm{K}$ is not very remarkable, the range $1.5 \leq\left(t_{3} / t_{2}\right) \leq 2.5$ allows small values of $\mathrm{K}(\mathrm{K}<35$ $\mathrm{MPa})$.

As a result, the parameters of the thickness transition in a pipe have an influence on the variations of $K$, precisely the parameters of the first thickness transition $\left(\boldsymbol{\alpha}_{1},\left(t_{2} / t_{1}\right)\right)$ are more influential on the gravity of defect compared to the second thickness transition $\left(\boldsymbol{\alpha}_{2},\left(t_{3} / t_{2}\right)\right)$.

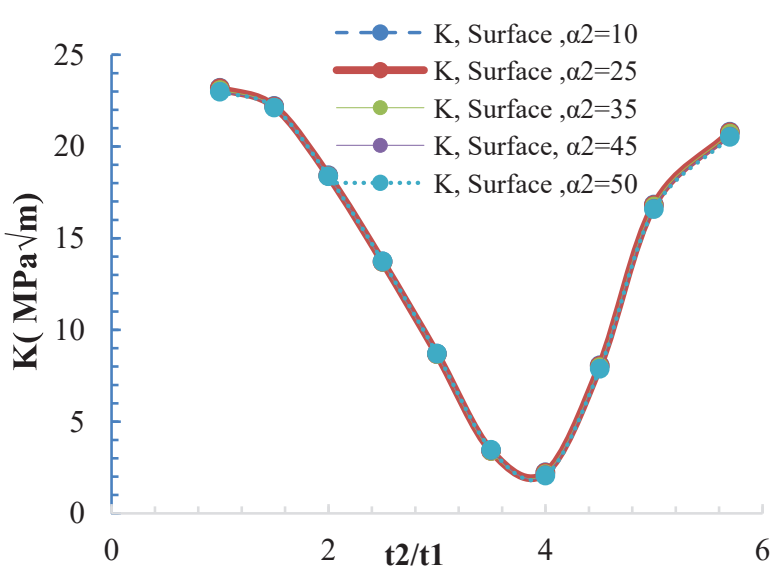

(a)

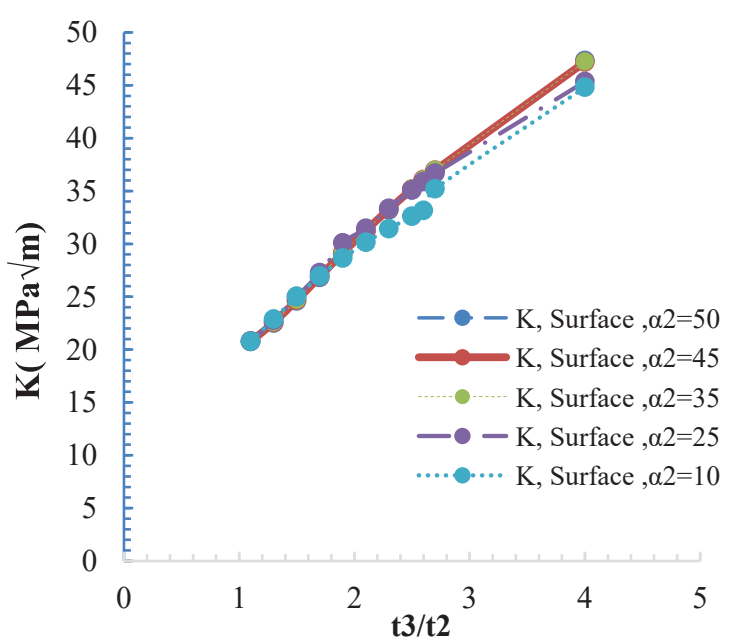

(c)

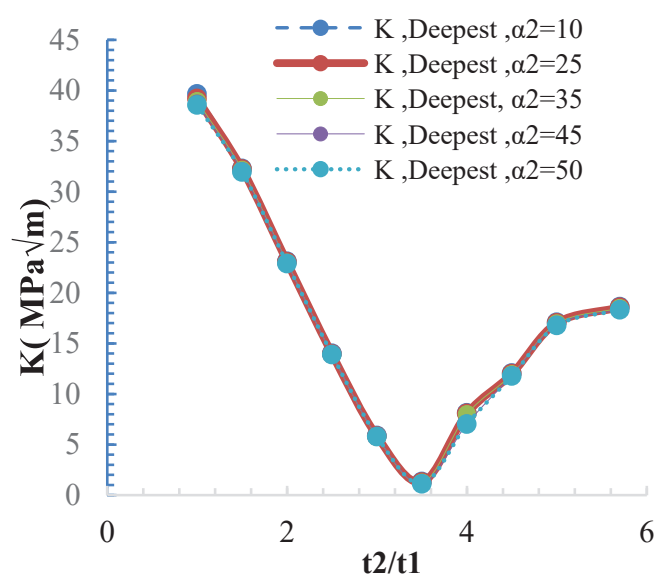

(b)

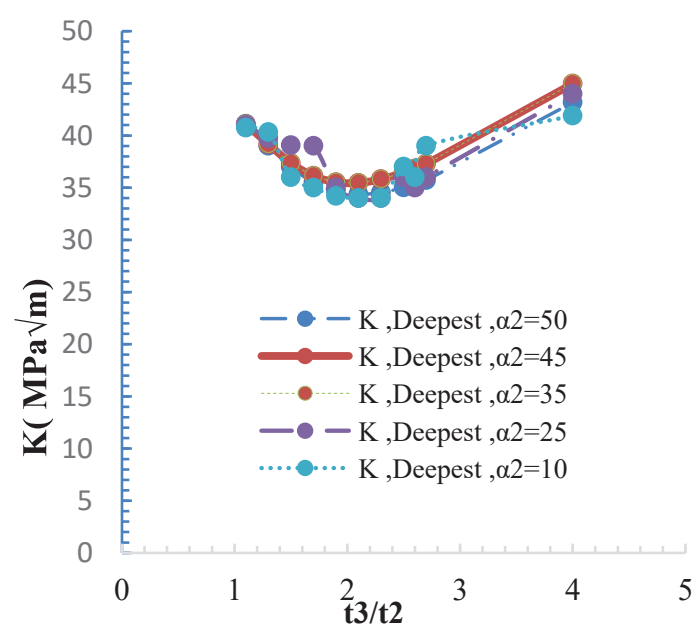

(d)

Fig. 16: Variation of $\mathrm{K}$ at deepest and surface points: (a-b) According to $\boldsymbol{\alpha}_{2}$ and $\left(\mathbf{t}_{2} / \mathbf{t}_{1}\right)$, (c- d) According to $\boldsymbol{\alpha}_{2}$ and $\left(\mathbf{t}_{3} / \mathbf{t}_{2}\right)$.

\section{CONCLUSION}

In this paper, we analysed the effect of an external circumferential elliptical crack located at the thickness transition zone of a pipe with double slopes. The study showed that for the surface and the deepest points, the angle $\boldsymbol{\alpha}_{1}=30^{\circ}$ and $1.1 \leq\left(t_{2} / t_{1}\right) \leq 1.5$ are grave cases of the first slope of the thickness transition. The angle $\alpha_{2}=45^{\circ}$ and ( $\left.t_{2} / t_{1}\right)=3.5$ lead to an increase in the value of $\mathrm{K}$ but in general, the effect of the son slope 
isn't remarkable, that is to say the parameters $\left(\boldsymbol{\alpha}_{1},\left(t_{2} / t_{1}\right)\right)$ are more influential than the parameters $\left(\boldsymbol{\alpha}_{2},\left(t_{3} / t_{2}\right)\right)$.

Considering the internal pressure, this work highlighted the investigation of a $3 \mathrm{D}$ crack problem in a thickness transition pipe using XFEM. In XFEM, level sets and enrichment zone were defined. A crack is easily modelled by enrichment functions. The comparison between the stress intensity factors showed that the pipe containing a thickness transition with double slopes is more sensitive to the considered cracks. The decreasing of the angle of slopes and the increase of the ratio of thickness is one effective method of reducing the SIF.

\section{REFERENCES}

[1] Rahman S, Ghadiali N, Wilcowski GM, Moberg F, Brickstad B. (1998) Crack-opening-area analysis for circumferential trough-wall cracks restrain of bending thickness transition and weld residual stresses. Int J Pres Ves Pip, 75(6):397-415.

[2] Hanan El Bhilat, Khalid El Had, Houda Salmi, Abdelilah Hachim. (In press). Thermomechanical characterization of post-consumer recycled high impact polystyrene from disposable cups: influence of the number of processing cycles. Journal of Computational \& Applied Research in Mechanical Engineering (JCARME). DOI 10.22061/JCARME.2019.5187.1643

[3] Abdelkader Saffih, Hariri S. (2006) Numerical study of elliptical cracks in cylinders with a thickness transition' International Journal of Pressure Vessels and Piping; 83(1):35-41. DOI: $10.1016 /$ j.ijpvp.2005.10.002

[4] Abdelkader Saffih, Hariri S. (2006) Comparison of semi-elliptical cracks in cylinders with a thickness transition and in a straight cylinder - Elastic-plastic behavior, Engineering Fracture Mechanics, 73(4):2685-2697

[5] Hariri S, El Hakimi A, Azari Z. (2008) Etude numérique et expérimentale de la nocivité des défauts dans des coques cylindriques et sphériques: aide à la détermination des facteurs de contraintes, Revue de Mécanique Appliquée et Théorique, 1(10):791-804. http://smsm.fsac.ac.ma/larevue/2008/art9vol1n10.pdf

[6] CEA; The French Alternative Energies and Atomic Energy Commission (CEA). 'Commissariat à L'Energie Atomique (France)' http://www.cea.fr/.

[7] CASTEM; [http://www-cast3m.cea.fr/]

[8] Chapuliot S, Lacire MH. (1999) Stress intensity factors for external circumferential cracks in tubes over a wide range of radius over thickness ratios. American Society of Mechanical Engineers, Pressure Vessels and Piping Division, 50(2):395-106. https://inis.iaea.org/collection/NCLCollectionStore/_Public/31/058/31058406.pdf

[9] Moës N, Gravouil A. Belytschko T. (2002) Non-planar 3D crack growth by the extended finite element and level sets; Part I: Mechanical model. International Journal for Numerical Methods in Engineering, 53(11):2549-2568. https://doi.org/10.1002/nme.429

[10] Salmi H, El Had K, El Bhilat H, Hachim A. (2020) Numerical Study of SIF for a Crack in P265GH Steel by XFEM. In: Dos Santos S., Maslouhi M., Okoudjou K. (eds) Recent Advances in Mathematics and Technology. Applied and Numerical Harmonic Analysis. Birkhäuser, Cham. doi.org/10.1007/978-3-030-35202-8_6

[11] Belytschko T, Black T. (1999). Elastic crack growth in finite elements with minimal remeshing, Int. J. Numer. Methods Eng, 45(5):601-62.

[12] Stolarska M, Chopp D, Moes N, Belytschko T. (2001) Modelling crack growth by level sets in the extended finite element method, Int. J. Numer. Methods Eng, 51(1):943-960.

[13] Seyed Javid Zakavi, Behzad Shiralivand, Mohammad Nourbakhsh. (2017) Evaluation of combined hardening model in ratcheting behavior of pressurized piping elbows subjected to in-plane moments. Journal of Computational \& Applied Research in Mechanical Engineering (JCARME); 7(1): 57-71. DOI 10.22061/JCARME.2019.5187.1643 
[14] Kamal Sharma IVS, Mishra BK, Bhasin V. (2014) Numerical Modeling of Part-Through Cracks in Pipe and Pipe Bend using XFEM, Procedia Materials Science, 6(2):72-79.

[15] Rice JR. (1968) A Path Independent Integral and the Approximate Analysis of Strain Concentration by Notches and Cracks, Journal of Applied Mechanics, 35(1):379-386.

[16] Sukumar N, Chopp DL, Moran B. (2003), Extended finite element method and fast marching method for three-dimensional fatigue crack propagation, Engineering Fracture Mechanics, 70(1): 29-48.

[17] Eshelby JD. (1956) The Continuum Theory of Lattice Defects, Solid State Physics, 3(2):79144.

[18] CODAP (2005); French construction code. Construction des Appareils à Pression non soumis à l'action de la flamme, 'the Code for Construction of unfired Pressure Vessels, Division 1, part C - design and calculation, section $\mathrm{C} 2$ - rules for calculating cylindrical, spherical and conical shell subjected to internal pressure.

[19] Houda Salmi, Khalid El Had, Hanan El Bhilat, Abdelilah Hachim. (2019). Numerical Analysis of the Effect of External Circumferential Elliptical Cracks in Transition Thickness Zone of Pressurized Pipes Using XFEM. J. Appl. Comput. Mech., 5(5):861-874.

DOI: 10.22055/JACM.2019.28043.1452.

[20] Houda Salmi ; Khalid El Had; Hanan El Bhilat; Abdelilah Hachim (In press). Numerical modeling and comparison study of elliptical cracks effect on the pipes straight and with thickness transition exposed to internal pressure, using XFEM in elastic behavior. Journal of Computational and Applied Research in Mechanical Engineering.

DOI: 10.22061/JCARME.2019.3597.1448. 